\title{
Acrylamide in coffee: Estimation of exposure from vending machines
}

\section{Mesias, F.J. Morales}

Institute of Food Science, Technology and Nutrition, ICTAN-CSIC, José Antonio Novais I0, 28040 Madrid, Spain

\begin{abstract}
The present study aimed to evaluate the levels of acrylamide in coffee brews acquired from coffee vending machines. Acrylamide content ranged from 7.7 to $40.0 \mu \mathrm{g} / \mathrm{L}$ (mean: $20.6 \mu \mathrm{g} / \mathrm{L}$ ). These levels are similar to those found in coffee brews prepared by other coffee machines with different extraction procedures. The dietary exposure of the Spanish population to acrylamide through coffee drinks was estimated at $0.037 \mu \mathrm{g} / \mathrm{kg}$ body weight/day (range $0.018-0.056 \mu \mathrm{g} / \mathrm{kg}$ body weight $/$ day). The maximum acrylamide exposure is lower than the value of $0.2 \mathrm{mg} / \mathrm{kg}$ body weight/day, defined as the lowest no observed adverse effect level (NOAEL) for a non-carcinogenic end-point. Therefore it may be suggested that exposure to acrylamide through vending machine coffees does not imply a high risk to public health. These data are useful to the different stakeholders involved in risk assessment, and in general to risk communicators, policy makers and the industry.
\end{abstract}

Chemical compounds described in this article: acrylamide (PubChem CID: 6579); potassium hexacyanoferrate(II) trihydrate (PubChem CID: 161067); zinc acetate dehydrate (PubChem CID: 2724192); methanol (PubChem CID: 887); formic acid (PubChem CID: 284).

KEYWORDS: Acrylamide, coffee, exposure, processing contaminants, food analysis, food composition, food safety

\section{INTRODUCTION}

Acrylamide is generated in several foods during processing as a consequence of the Maillard reaction and specifically as the result of the reaction between asparagine and reducing sugars as the main precursors (Stadler and Scholz, 2004). Recently the European Food Safety Authority (EFSA) has confirmed that the presence of acrylamide in food is a public health concern, requiring continued efforts to reduce its exposure (EFSA, 2015).

According to the EFSA, coffee together with processed potatoes and cereal based food, are the main sources of exposure to acrylamide in the diet of adults (EFSA, 2014). Coffee is generally roasted at temperatures in the range of $220-250^{\circ} \mathrm{C}$, triggering the Maillard reaction. This reaction is responsible for the changes in the sensory properties but also for the formation of acrylamide from its precursors naturally present in the coffee bean.

The extent of acrylamide formation in coffee depends on initial concentrations of precursors and their ratio in the green bean. The roasting and storage conditions also affect the formation. For instance, Robusta beans contain higher levels of asparagine than Arabica, which results in higher levels of acrylamide after roasting (Lantz et al., 2006). Regarding the roasting conditions, acrylamide increases in the first stages of roasting and then declines with time and temperature. This is probably due to the consumption of the precursors meaning that the loss of acrylamide from physical and chemical degradation predominates against its formation (Taeymans et al., 2004). Longer periods of storage also lead to a loss of acrylamide levels in roasted coffee (Hoenicke and Gatermann, 2005).

In order to regulate and control the risk associated with acrylamide intake, the European Commission (EC) established recommendations on the monitoring of acrylamide levels in foods (EC, 2010) and 
adopted indicative values to control acrylamide content in certain foodstuffs. References values for coffee according to the latest EC Recommendation (2013/647/EU) are $450 \mu \mathrm{g} / \mathrm{kg}$ for roasted coffee and $900 \mu \mathrm{g} / \mathrm{kg}$ for instant coffee (EC, 2013). Concentrations in a range of 197-256 $\mu \mathrm{g} / \mathrm{kg}$ for roasted coffee and 229-II $23 \mu \mathrm{g} / \mathrm{kg}$ for instant coffee have been reported (EFSA, 2012). However, since coffee is not consumed as a powder, but as drink, it is important to estimate the real acrylamide exposure through the consumption of coffee. The main factors that affect acrylamide contents in the beverage are the coffee variety, ripeness of the coffee bean, roasting conditions, storage and beverage preparation (Soares et al., 2015).

Acrylamide is extracted efficiently due to its high polarity and water solubility (Andrzejewski et al., 2004). Nevertheless, the level of extraction is also affected by factors such as water temperature, time of contact with ground coffee and pressure applied, all of which are conditioned by the type of coffee machine used. Levels of acrylamide from 1.7 to $75.0 \mu \mathrm{g} / \mathrm{L}$ have been found in coffee brews prepared with different extraction methods (Andrzejewski et al., 2004; Șenyuva and Gökmen, 2005; Alves et al., 2010; Sirot et al., 2012). In agreement with Alves et al. (2010), it is more realistic to evaluate the exposure to acrylamide by analyzing the beverage rather than the ground coffee before preparation.

The aim of this study was to determine levels of acrylamide in coffee acquired from coffee vending machines. These beverages make a significant contribution to the coffee intake outside the home. This research has been intentionally limited to commercially available automatic coffee vending machines placed in busy public areas, such as train and bus stations, hospitals and universities, to estimate the exposure in real life conditions where the consumer does not have any impact on the preparation of the drink. Finally, the dietary exposure to acrylamide by the Spanish population through coffee machines was estimated.

\section{MATERIALS AND METHODS}

\section{Chemicals}

Acrylamide standard (99\%), potassium hexacyanoferrate(II) trihydrate (98\%), zinc acetate dehydrate (99.5-101\%) and methanol (HPLC grade) (99.9\%) were purchased from Sigma-Aldrich (St. Louis, MO). $\left[{ }^{13} \mathrm{C}_{3}\right]$-Acrylamide (isotopic purity 99\%) was from Cambridge Isotope Labs (Andover, MA). Formic acid (98\%) was from Panreac (Barcelona, Spain). Milli-Q water used was produced using an Elix3 Millipore water purification system coupled to a Milli-Q module (model Advantagel0; Millipore, Molsheim, France). All other chemicals, solvents and reagents were of analytical grade. Reversed-phase Oasis-HLB cartridges $(30 \mathrm{mg}, \mathrm{I} \mathrm{mL}$ ) were from Waters (Milford, MA). Syringe filter units $(0.45 \mu \mathrm{m}$, cellulose) were purchased from Análisis Vínicos (Tomelloso, Spain).

\section{Coffee samples}

Forty-one espresso coffee brew samples were acquired from different coffee vending machines in the Autonomous Community of Madrid (Spain). The vending machines were located in public areas with a high footfall of people, including hospitals, train and bus stations, universities, etc. All machines were different, involving different brewing procedures, types of coffee bean and roasting and different coffee/water ratios for extraction. The machines belonged to twelve of the most relevant companies that provide vending services in Spain. Fresh coffee samples were stored in $100 \mathrm{~mL}$ double-sealed containers and refrigerated at $4^{\circ} \mathrm{C}$ for a maximum of three days until analysis. Volume of coffee beverage was measured.

\section{Measurement of pH}

$\mathrm{pH}$ was measured in coffee brews by using a pH meter at ambient temperature (CG-837 pH meter, Schott, Mainz, Germany). 


\section{Determination of dry weight}

Dry weight was determined gravimetrically. $2 \mathrm{~mL}$ of each sample was accurately weighed and then dried to a constant weight in an oven at $105^{\circ} \mathrm{C}$ for $24 \mathrm{~h}$ according to the Association of Official Analytical Chemists (AOAC) method (1995).

\section{Determination of browning}

Browning intensity was measured at $405 \mathrm{~nm}$ using a SynergyTM HT-multimode microplate spectrophotometer (BioTek Instruments, Winooski, VT) (Silván et al., 2010). I mL of coffee brew was clarified with $20 \mathrm{~mL}$ each of Carrez-I (I5 g potassium hexacyanoferrate(II) trihydrate/ $100 \mathrm{~mL}$ water) and Carrez-II ( $30 \mathrm{~g}$ zinc acetate dihydrate/ $100 \mathrm{~mL}$ water) solutions and centrifuged ( $9000 \mathrm{x} \mathrm{g}$ for $10 \mathrm{~min}$ ) at $4^{\circ} \mathrm{C}$. Supernatant was diluted appropriately with water in order to obtain an absorbance reading less than 1.5 arbitrary units. All measurements were made in triplicate. Results were expressed as absorbance units $/ \mathrm{mL}$ coffee.

\section{Determination of acrylamide by liquid chromatography- electrospray ionization-tandem mass spectrometry (LC-ESI-MS-MS)}

Acrylamide was determined by the method described by Mesías et al. (2015) with minor modifications. Five-milliliter aliquots of each coffee brew samples were mixed with $4.4 \mathrm{~mL}$ of water in polypropylene centrifuge tubes. Mixture was spiked with $100 \mu \mathrm{L}$ of a $5 \mu \mathrm{g} / \mathrm{mL}\left[{ }^{13} \mathrm{C}_{3}\right]$-acrylamide methanolic solution as internal standard and later homogenized using an Ultra Turrax (IKA, Staufen, Germany) for 10 min. Afterwards, each sample was treated with $250 \mu \mathrm{L}$ of each Carrez I and Carrez II solutions and centrifuged $(9000 \times \mathrm{g}$ for $10 \mathrm{~min})$ at $4^{\circ} \mathrm{C}$ (Hettich Zentrifugen, Tuttlingen, Germany). Samples were cleaned up with Oasis-HLB cartridges (Waters Corp., Milford, MA). Cartridges were preconditioned with I $\mathrm{mL}$ of methanol and I $\mathrm{mL}$ of water. An aliquot of the clear supernatant $(\mathrm{I} \mathrm{mL})$ was loaded onto the cartridge at a flow rate of $2 \mathrm{~mL} / \mathrm{min}$ and first drops were discarded and the rest collected. Solution was filtered through a $0.45 \mu \mathrm{m}$ filter into an amber LC- MS vial. An Agilent 1200 liquid chromatograph coupled to an Agilent Triple Quadrupole MS detector (Agilent Technologies, Santa Clara, CA) with positive electrospray ionization was used. Sample $(10 \mathrm{~mL})$ was separated on a Hypercarb column $(50 \mathrm{x}$ $2.1 \mathrm{~mm}, 5 \mu \mathrm{m}$; Thermo Scientific, Bremen, Germany) at $30^{\circ} \mathrm{C}$ with formic acid in water eluant $(0.2$ $\mathrm{mL} / 100 \mathrm{~mL}$ ) at a flow rate of $0.4 \mathrm{~mL} / \mathrm{min}$. The transitions m/z $72 \rightarrow \mathrm{m} / \mathrm{z} 55$ and m/z $75 \rightarrow \mathrm{m} / \mathrm{z} 58$ were monitored for acrylamide and $\left[{ }^{13} \mathrm{C}_{3}\right]$-acrylamide, respectively; fragmentation voltage was set at $76 \mathrm{~V}$ and the collision energy at $8 \mathrm{~V}$. The limit of quantification was set at $5 \mu \mathrm{g} / \mathrm{L}$. The accuracy of the results has been recently demonstrated in an interlaboratory comparison study launched by the Food Analysis Performance Assessment Scheme (FAPAS) program (2015). FAPAS Proficiency Test 3056 corresponding to crispbread test material was analyzed, yielding a z-score of 0.3 . Precision (reproducibility) was less than $10 \%$ and recovery between 96 and $110 \%$. Results were expressed as $\mu \mathrm{g} / \mathrm{L}$ of beverage.

\section{Statistical analysis}

Statistical analysis was performed using Statgraphics Centurion XV (Herndon, VA). Data were expressed as mean \pm standard deviation (SD). Relationships between the different parameters analyzed were evaluated by computing Pearson linear correlation coefficients at the $p<0.05$ confidence level.

\section{RESULTS AND DISCUSSION}

\section{Characterization of the coffee brews}

Coffee brews were characterized by $\mathrm{pH}$, dry weight and browning. The $\mathrm{pH}$ values of the coffee brews ranged from 5.0 to 5.7 , dry weight from I.2\% to $8.7 \%$ and browning from 1.3 to 5.8 units of absorbance (data not shown). The characteristics of coffee brews depend on variables such as green bean composition, roasting conditions, grinding, coffee/water ratio, brewing procedure, contact times and water temperature (Petracco, 2005). In the present study, coffee beverages were acquired from the most representative brands of coffee vending machines in the Spanish market. These machines differ 
largely according to the technology applied, design, coffee origin, intensity of roasting and extraction conditions. Because of this, the coffee brews possessed different characteristics. This variability represents the broad scenario of coffee consumption from automatic vending services.

\section{Acrylamide levels in coffee brews}

Acrylamide levels in the coffee brews acquired from coffee vending machines ranged from 7.7 to 40.0 $\mu \mathrm{g} / \mathrm{L}$, with a mean value of $20.6 \mu \mathrm{g} / \mathrm{L}$ (Table I,Fig. I). All the samples contained acrylamide levels above the limit of quantification ( $L O Q=5 \mu g / L)$. Data distribution showed a high variability in the acrylamide content among samples and two outliers were identified $(36.0 \mu \mathrm{g} / \mathrm{L}$ and $39.9 \mu \mathrm{g} / \mathrm{L})$. This broad distribution in the acrylamide content is probably a consequence of the type of roasted coffee and the different conditions used to brew the coffee.

The procedures to prepare a coffee brew are usually based on three different processes: decoction, infusion and pressure (Soares et al., 2015). In the decoction, ground coffee is kept in contact with water for a period of time, the extraction increasing with time of contact and water temperature. In infusion preparations, hot water flows through the ground coffee during a short period of time and, in consequence, extraction is lower than in the decoction method (Petracco, 200I). Finally, the pressure method is used to prepare espresso coffee. In this case, hot water is percolated under high pressure through ground coffee for a very short time, which may result in an incomplete extraction of acrylamide. However, due to the high coffee/water ratio used to prepare espresso coffee, the final acrylamide content may be higher than in other coffee brews. Table 2 summarizes the acrylamide levels measured in coffee beverages prepared by different extraction methods as described in the literature. Although in the present study some samples showed an acrylamide content lower than $10 \mu \mathrm{g} / \mathrm{L}$, most of the coffee brews presented acrylamide values within the range reported for other espresso coffees and, as expected, higher than those observed in filter and French press cafetiere coffees.

Assuming that coffee beverages were prepared from $7.5 \mathrm{~g}$ of ground roasted coffee per $40 \mathrm{~mL}$ of water (Andueza et al., 2003) and considering that the extractability of acrylamide ranged from 92 to $99 \%$ (Alves et al., 2010), the content of acrylamide in the ground coffee from which beverages were prepared could range from 41.5 to $232 \mu \mathrm{g} / \mathrm{kg}$. This range is close to that reported by EFSA (2010) in roasted coffee $(197-256 \mu \mathrm{g} / \mathrm{kg}$ ) and no samples exceeded the indicative value of $450 \mu \mathrm{g} / \mathrm{kg}$ according to the recommendations of the European Commission (EC, 2013). However this statement is based on an approximate calculation, and has to be further confirmed, since no information about the coffee brew preparation conditions is available.

Possible relationships between $\mathrm{pH}$, dry weight, browning and acrylamide content were analyzed. However, no significant correlations were observed.

\section{Estimation of acrylamide exposure from coffee brews}

Exposure to acrylamide from drinking coffee was estimated, taking into account the range of concentrations observed among the different samples. Initially levels in the drinks were normalized to the volume of the beverage dispensed by each automatic machine. Volumes ranged from 40 to 100 $\mathrm{mL} /$ cup, which led to a total acrylamide content ranging from 0.8 to $2.4 \mu \mathrm{g} /$ cup. The average for the acrylamide level in the forty-one samples was $1.6 \mu \mathrm{g} /$ cup (Table I).

If we consider that the average coffee consumption for the Spanish population is 599 cups/person/year as reported by the Spanish Coffee Federation (SCF, 2013), corresponding to 1.64 cups of coffee/person/day, then the mean daily acrylamide intake would be $2.6 \mu \mathrm{g} /$ person/day (range: 1.3-3.9 $\mu \mathrm{g} /$ person/day). Assuming a default value of $70 \mathrm{~kg}$ of body weight (bw) for an adult according to EFSA Scientific Committee (EFSA SC, 20I2), the acrylamide intake from coffee would range from 0.018 to 
$0.056 \mu \mathrm{g} / \mathrm{kg}$ bw/day (mean: $0.037 \mu \mathrm{g} / \mathrm{kg} \mathrm{bw} / \mathrm{day}$ ). These results are similar to the daily intake of acrylamide from coffee estimated for adults from The Netherlands $(0.048 \mu \mathrm{g} / \mathrm{kg} \mathrm{bw} / \mathrm{day})$. Lower estimates have been reported for adults from Ireland $(0.004 \mu \mathrm{g} / \mathrm{kg}$ bw/day), United Kingdom (0.005 $\mu \mathrm{g} / \mathrm{kg} \mathrm{bw} /$ day $)$ and Latvia $(0.029 \mu \mathrm{g} / \mathrm{kg}$ bw/day) whereas higher exposures have been found for Denmark $(0.106 \mu \mathrm{g} / \mathrm{kg} \mathrm{bw} /$ day), France $(0.168 \mu \mathrm{g} / \mathrm{kg}$ bw $/$ day) and Sweden $(0.17 \mathrm{\mu g} / \mathrm{kg} \mathrm{bw} /$ day) (Arisseto and Toledo, 2008). Obviously, these exposures depend on the consumption habits of the population since coffee consumption is widely variable between different countries and regions. An average consumption of coffee from $210 \mathrm{~mL} /$ day in the Polish adult population to as much as 1100 and $900 \mathrm{~mL} /$ day for Danish men and women (35-44 years age group), respectively, has been described (Granby and Fagt, 2004; Mojska et al., 2010).

Table 3 shows a summary of the acrylamide exposure through the consumption of both roasted coffee beverages and instant coffee in adults and adolescents from several countries, according to the recent review published by Arisseto and Vicente (2015). As observed, the results found in the present study lie within the range of exposure to acrylamide from roasted coffee for average coffee consumers $(0.003-$ $0.171 \mu \mathrm{g} / \mathrm{kg}$ bw/day). Therefore it can be deduced that the exposure of humans to acrylamide from coffee vending machines is similar to that of other coffee preparations.

To our knowledge, there are no studies on the exposure of the Spanish population to acrylamide. The most approximate evaluation has been published by Delgado-Andrade et al. (2012) for Spanish male adolescents consuming a traditional and balanced diet, where the total acrylamide intake was estimated to be $0.534 \mu \mathrm{g} / \mathrm{kg} \mathrm{bw} / \mathrm{day}$. If these estimations are taken into account, coffee would account for $7.5 \%$ of the total acrylamide intake. This result falls within the range of contribution of roasted coffee to the total acrylamide intake for both adults and adolescents who are average coffee consumers (Arisseto and Vicente, 2015).

In order to calculate the potential risk for human health through the consumption of acrylamide from coffee beverages, EFSA and JECFA (Joint Food and Agricultural Organization of the United Nations/World Health Organization (FAO/WHO) Expert Committee on Food Additives) have suggested using the MOE value, defining the margin of exposure (MOE) as the value calculated by dividing the dose causing cancer in animal studies by exposure of humans to acrylamide (FAO/WHO, $20 \mathrm{II})$. In this respect, a MOE value of 8378 was obtained when comparing the mean exposure with the established BMDLIO (benchmark dose lower confidence limit 10\%) for mammary tumors in female rats $(0.31 \mathrm{mg} / \mathrm{kg}$ bw $/$ day $)$ and 4865 when the comparison is with the BMDLIO for Harderian gland tumors in male mice $(0.18 \mathrm{mg} / \mathrm{kg}$ bw/day). The EFSA Scientific Committee considers that, for substances that are both genotoxic and carcinogenic, an MOE of 10,000 or higher is of low concern from a public health point of view (EFSA, 2015). Since the calculated MOE values are lower than 10000, it may be suggested that exposure to acrylamide through coffee consumption could imply a risk to public health. However, the maximum acrylamide exposure estimated in our study is much less than both the value of $0.2 \mathrm{mg} / \mathrm{kg}$ bw/day, defined as the lowest no observed adverse effect level (NOAEL) for a non-carcinogenic endpoint $(\mathrm{FAO} / \mathrm{WHO}, 20 \mathrm{II})$ and the value of $2.6 \mu \mathrm{g} / \mathrm{kg}$ bw/day estimated as the tolerable daily intake linked with the development of cancer (Tardiff et al., 2010). Therefore, it may be concluded that coffee consumption does not involve a high risk, although these conclusions should be revised for heavy coffee consumers (more than 5 cups/day). To avoid possible risk it is advisable to reduce acrylamide content in coffee and, consequently the dietary exposure to acrylamide, considering certain preventive actions and mitigation strategies.

\section{CONCLUSIONS}

The differences observed in the acrylamide content of coffee brew may result from the different roasted coffees used and the different conditions of preparation in the coffee vending machines. Consumption of 
coffee brew acquired from vending services contributes to the acrylamide exposure in humans in a way similar to other coffee brew preparations. The dietary exposure of the Spanish population to acrylamide through coffee beverages does not imply a high risk to human health. However, since coffee brew is considered one of the most important contributors to acrylamide exposure in the diet of adults, it is necessary to define potential strategies to reduce the content of acrylamide in coffee. These findings are useful for risk assessment analyses in the Spanish population. Conflict of interest The authors have no conflict of interest.

\section{ACKNOWLEDGMENT}

This research was partly funded by projects SI0I3/ABI-3028- AVANSECAL (Comunidad de Madrid and FEDER program) and Spanish National Research Council (CSIC-201370E027). The authors thank to Ms. I. Alvarez and Mr. MA. Martinez for their technical assistance.

\section{REFERENCES}

AOAC (Association of Official Analytical Chemists), 1995. Official Methods of Analysis of AOAC International. Association of Official Analytical Chemists, Washington, D.C.

Alves, R.C., Soares, C., Casal, S., Fernandes, J.O., Beatriz, M., Oliveira, P.P., 20I0. Acrylamide in espresso coffee influence of species, roast degree and brew length. Food Chem. 119, 929-934.

Andrzejewski, D., Roach, J.A., Gay, M.L., Musser, S.M., 2004. Analysis of coffee for the presence of acrylamide by LC-MS/MS. J. Agric. Food Chem. 52, 1996-2002.

Andueza, S., Maeztu, L., Pascual, L., Ibáñez, C., de Peña, M.P., Cid, C., 2003. Influence of extraction temperature on the final quality of espresso coffee. J. Sci. Food Agric. 83, 240-248.

Arisseto, A.P., Toledo, M.C.F., 2008. Preliminary estimate of acrylamide intake in Brazil. Braz. J. Toxicol. 2I, 9-14.

Arisseto, A.P., Vicente, E., 2015. Estimate of acrylamide intake from coffee and health risk assessment. In: Preddy, V.R. (Ed.), Coffee in Health and Disease Prevention. Academic Press, London, UK, Pp. 575584.

Delgado-Andrade, C., Mesías, M., Morales, F.J., Seiquer, I., Navarro, M.P., 2012. Assessment of acrylamide intake of Spanish boys aged II-14 years consuming a traditional and balanced diet. LWT Food Sci. Technol. 46, 16-22.

EC (European Commission), 2010. Commission recommendation of 3 May 2007 on the monitoring of acrylamide levels in food (2007/33 I/EC). Off. J. Eur. Union L I 23 (accessed I2.05.07).

EC (European Commission), 2013. Commission Recommendation of 8 November 2013 on Investigations Into the Levels of Acrylamide in Food. EC (European Commission) http://eurlex.europa.eu/LexUriServ/LexUriServ.do?uri=OJ: L:2013:301:0015:0017:EN:PDF (accessed 27.10.15).

EFSA (European Food Safety Authority), 2010. Scientific document: update of results on the monitoring of furan levels in food. EFSA J. 8, 1702 http://www.efsa. europa.eu/sites/default/files/scientific_output/files/main_documents/1702.pdf (accessed 08.10. 15).

EFSA (European Food Safety Authority), 2012. Update on acrylamide levels in food from monitoring years 2007 to 2010. EFSA J. 10, 2938 http://www.efsa.europa. eu/sites/default/files/scientific_output/files/main_documents/2938.pdf (accessed 14.10.15).

EFSA (European Food Safety Authority), 2014. Draft Scientific Opinion on Acrylamide in Food. EFSA (European Food Safety Authority) http://www.efsa. europa.eu/en/consultations/call//4070I.pdf (accessed 14.10.15).

EFSA (European Food Safety Authority), 2015. Scientific opinion on acrylamide in food. EFSA J. 13, 4104 http://www.efsa.europa.eu/sites/default/files/ scientific_output/files/main_documents/4104.pdf (accessed 07.10.15).

EFSA SC (European Food Safety Authority Scientific Committee), 2012. Guidance on selected default values to be used by the EFSA Scientific Committee, 2012. Scientific panels and units in the absence of 
$\begin{array}{lllll}\text { actual data. } & \text { EFSA } & \text { J. } & 10, & 2579\end{array}$ http://www.efsa.europa.eu/sites/default/files/scientific_output/files/main_documents/2579.pdf (I 3.0I.I6). FAO/WHO (Food and Agricultural Organization of the United Nations/World Health Organization), 20II. World Health Organization; Food and Agriculture Organization of the United Nations, Geneva; Rome.

Granby, K., Fagt, S., 2004. Analysis of acrylamide in coffee and dietary exposure to acrylamide from coffee. Anal. Chim. Acta 520, I77-182.

Hoenicke, K., Gatermann, R., 2005. Studies on the stability of acrylamide in food during storage. J. AOAC Int. 88, 268-273.

Lantz, I., Ternite, R., Wilkens, J., Hoenicke, K., Guenther, H., van der Stegen, G., 2006. Studies on acrylamide levels in roastings, storage and brewing of coffee. Mol. Nutr. Food Res. 50, 1039-I046.

Mesías, M., Holgado, F., Márquez-Ruiz, G., Morales, F.J., 2015. Effect of sodium replacement in cookies on the formation of process contaminants and lipid oxidation. LWT Food Sci. Technol. 62, 633-639.

Mojska, H., Gielecinska, I., Szponar, J., Ołtarzewski, M., 2010. Estimation of the dietary acrylamide exposure of the Polish population. Food Chem. Toxicol. 48, 2090-2096.

Petracco, M., 200I. Technology IV: beverage preparation: brewing trends for the new millennium. In: Clarke, R.J., Vitzthum, O.G. (Eds.), Coffee, Recent Developments. Blackwell Science, Ltd., Oxford, UK, Pp. 140-164.

Petracco, M., 2005. The cup. In: Illy, A., Viani, R. (Eds.), Espresso Coffee: The Science of Quality. Elsevier Academic Press, Italy, pp. 290-298.

SCF (Spanish Coffee Federation) (20I3). http://www.federacioncafe.com/home.asp (accessed 02.II.I5.).

Silván, J.M., Morales, F.J., Saura-Calixto, F., 2010. Conceptual study on Maillardized dietary fiber in coffee. J. Agric. Food Chem. 58, 12244-12249.

Sirot, V., Hommet, F., Tard, A., Leblanc, J.C., 2012. Dietary acrylamide exposure of the French population: results of the second French total diet study. Food Chem. Toxicol. 50, 889-894.

Soares, C., Cunha, S., Fernandes, J., 2006. Determination of acrylamide in coffee and coffee products by GC-MS using an improved SPE clean-up. Food Addit. Contam. 23, I276-I 282.

Soares, C., Alves, R.C., Oliveira, M.B., 2015. Factors affecting acrylamide levels in coffee beverages. In: Preddy, V.R. (Ed.), Coffee in Health and Disease Prevention. Academic Press, London, UK, Pp. 217-224. Stadler, R.H., Scholz, G., 2004. Acrylamide: an update on current knowledge in analysis, levels in food, mechanisms of formation, and potential strategies of control. Nutr. Rev. 62, 449-467.

Șenyuva, H.Z., Gökmen, V., 2005. Study of acrylamide in coffee using an improved liquid chromatography mass spectrometry method: investigation of colour changes and acrylamide formation in coffee during roasting. Food Addit. Contam. 22, 214-220.

Taeymans, D., Wood, J., Ashby, P., Blank, I., Studer, A., Stadler, R.H., Gondé, P., Van Eijck, P., Lalljie, S., Lingnert, H., Lindblom, M., Matissek, R., Müller, D., Tallmadge, D., O'Brien, J., Thompson, S., Silvani, D., Whitmore, T., 2004. A review of acrylamide: an industry perspective on research, analysis, formation, and control. Crit. Rev. Food Sci. Nutr. 44, 323-347.

Tardiff, R.G., Gargas, M.L., Kirman, C.R., Carson, M.L., Sweeney, L.M., 20I0. Estimation of safe dietary intake levels of acrylamide for humans. Food Chem. Toxicol. 48, 658-667. 
FIGURES AND TABLES

Table I. Acrylamide content in coffee brew samples and estimations of acrylamide exposure.

\begin{tabular}{lrrrrr}
\hline & Mean \pm SD & Median & Minimum & Maximum & $\mathrm{P90}^{\mathrm{a}}$ \\
\hline Acrylamide content & & & & & \\
$\mu \mathrm{g} / \mathrm{L}$ & $20.6 \pm 6.9$ & 20.9 & 7.7 & 40.0 & 27.4 \\
$\mu \mathrm{g} / \mathrm{cup}^{\mathrm{b}}$ & $1.6 \pm 0.4$ & 1.6 & 0.8 & 2.4 & 2.0 \\
& & & & & \\
Acrylamide exposure & & & & & \\
$\mu \mathrm{g} /$ person/day & $2.6 \pm 0.7$ & 2.7 & 1.3 & 3.9 & 3.3 \\
$\mu \mathrm{g} / \mathrm{kg}$ bw/day & $0.04 \pm 0.01$ & 0.04 & 0.02 & 0.06 & 0.05 \\
\hline
\end{tabular}

Results are expressed as mean \pm standard deviation $(S D)(n=4 I)$. a P90: 90th percentile. b Volumes ranged from 40 to $100 \mathrm{~mL} /$ cup. c bw: body weight.

Table 2. Acrylamide levels ( $\mu \mathrm{g} / \mathrm{L})$ in coffee brews.

\begin{tabular}{llll}
\hline Coffee brews & Method determination & Acrylamide levels & Reference \\
\hline Turkish coffee & LC-MS/MS $^{\text {a }}$ & $29.0-75.0$ & Senyuva and Gökmen (2005) \\
Espresso coffee & GC-MS & $33.2-42.3$ & Alves et al. (2010) \\
& GC-MS & $11.4-36.2$ & Soares et al. (2006) \\
Filter coffee & LC-MS/MS & $1.7-14.0$ & Andrzejewski et al. (2004) \\
& LC-MS/MS & $3-15$ & Granby and Fagt (2004) \\
& GC-MS/MS & $5-14$ & Mojska et al. (2010) \\
French press cafetiere & LC-MS/MS & $2-16$ & Granby and Fagt (2004) \\
Brewed coffee & LC-MS/MS & $37 \pm 3$ & Sirot et al. (2012) \\
\hline
\end{tabular}

a LC-MS/MS: liquid chromatography-tandem mass spectrometry. b GC-MS: gas chromatography-mass spectrometry. c Extraction method not specified

Table 3. Summary of acrylamide exposure and contribution to the total acrylamide intake through the consumption of roasted coffee beverages and instant coffee, as revised by Arisseto and Vicente (2015).

\begin{tabular}{|c|c|c|c|c|}
\hline \multirow[t]{2}{*}{ Population groups } & \multicolumn{2}{|c|}{ Roasted coffee } & \multicolumn{2}{|c|}{ Instant coffee } \\
\hline & Average consumers & High consumers & Average consumers & High consumers \\
\hline \multicolumn{5}{|l|}{ Adults } \\
\hline Exposure $\left(\mu \mathrm{g} / \mathrm{kg} \mathrm{bw}^{\mathrm{a}} / \mathrm{day}\right)$ & $0.003-0.171$ & $0.059-0.456$ & $0.000-0.116$ & $0.010-0.565$ \\
\hline Contribution (\%) & $0.5-41.4$ & |4-44.5 & $0.0-17.0$ & Up to 55.2 \\
\hline \multicolumn{5}{|l|}{ Adolescents } \\
\hline Exposure ( $\mu g / \mathrm{kg}$ bw/day) & $0.000-0.012$ & $0.000-0.223$ & $0.000-0.007$ & $0.000-0.166$ \\
\hline Contribution (\%) & $0.0-9.0$ & Up to 17.5 & $0.0-0.9$ & n.a. ${ }^{b}$ \\
\hline
\end{tabular}

a bw: body weight. b n.a. not available. 
Fig. I. Box- and whisker plot and distribution graph for the acrylamide content in coffee brews acquired from coffee vending machines. Figure represents the distribution of acrylamide content in $4 \mathrm{I}$ different coffee brews. Values are mean \pm standard deviation $(S D)(n=2)$. Dotted line represents limit of quantification (LOQ).

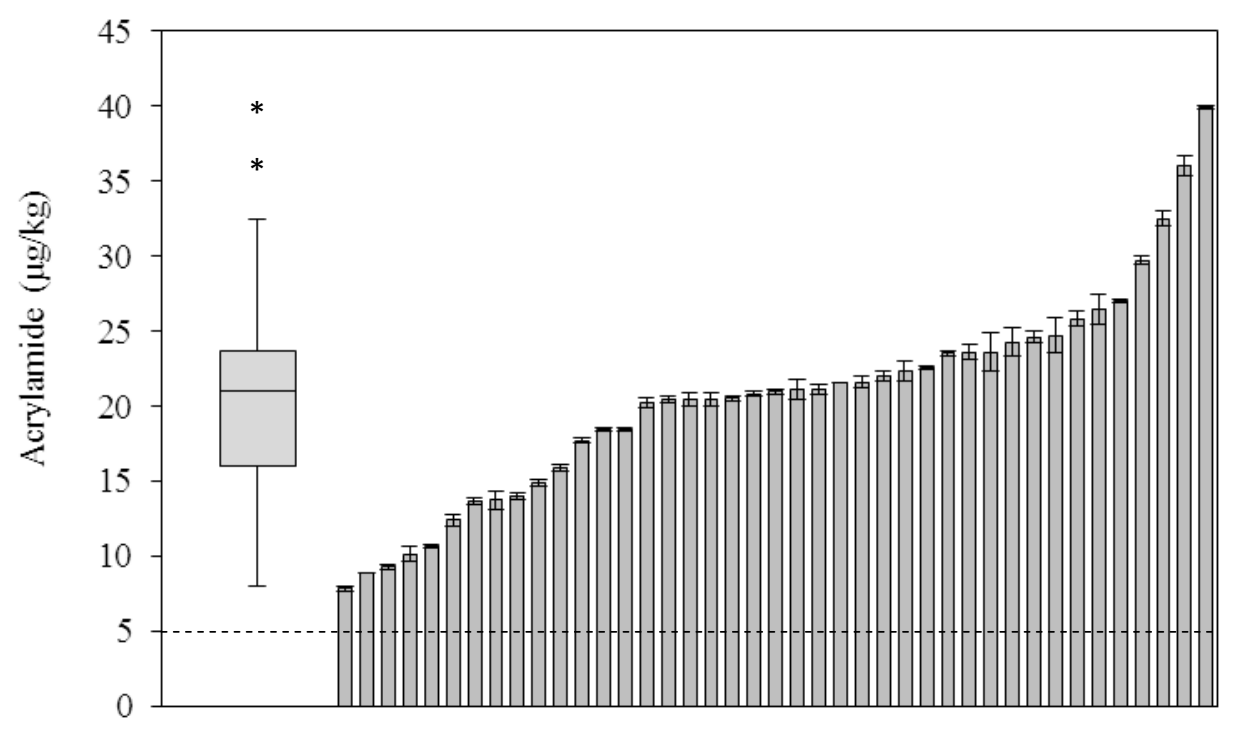

